Having gained his initial education in that city, Keith studied medicine in London and Leipzig, eventually becoming professor at the Royal College of Surgeons. As a noted research worker in anatomy and embryology, Keith was elected a Fellow of the Royal Society in 1913, and 4 years later he was appointed to the Fullerian chair at the Royal Institution. He was well known for his work on the development of early man and was an authority on fossil man. Keith wrote some attractive books, among them being Human Embryology and Morphology (1901), Ancient Types of Man, Antiquity of Man and A New Theory of Evolution, published in 1948. His presidential address to the British Association for the Advancement of Science in 1927 was an outstanding revision of the Darwinian theory. Despite his wide field of activities, Keith remained a staunch Aberdonian at heart, so that it is not surprising that he was Rector of Aberdeen from 1930 until 1933.

\section{New Variable Energy Cyclotron at Harwell}

THe first stages of commissioning a new variable energy cyclotron have been carried out successfully and rapidly at the Atomic Energy Research Establishment, Harwell. Within $24 \mathrm{~h}$ of switching on the machine, the beam was accelerated to the full radius. The difficult task of extracting the beam for experimental use has yet to come and the immediate programme is designed to explore the behaviour of the machine and to gain experience with it under various operating conditions. The cyclotron, with its buildings, research and development, will cost $£ 1,650,000$; it is to be initially used for studies of radiation damage, radiation chemistry and radiochemistry. The accelerator is a 70 -in. spiral-ridge cyclotron designed to accelerate ions of up to about mass 40. The design provides for an internal beam of up to $1 \mathrm{~m}$.amp. of $50-\mathrm{M} \odot \mathrm{V}$ protons (ultimately up to 100 m.amp. externally) and microampere beams of heavy ions, with energies in some cases up to $10 \mathrm{MeV}$ per nucleon. A beam of $22 \cdot 7-\mathrm{MeV}$ ions was initially accelerated to the full extraction radius while the beam current was deliberately restricted to 2 uamp. Energies of as high as $50 \mathrm{MeV}$ have since been achieved with currents of 20 m.amp. There are nine positions in which samples may be irradiated, one of which is on a probe in the internal beam. The external beam may strike a target in the cyclotron vault or be deflected by a bending magnet to any one of seven positions in three separate target rooms adjacent to the vault. The target rooms are shielded from one another and from the main vault so that experiments can be set up in one while irradiation proceeds in another. During operations the machine and targets can be observed from the control room through a water. filled window or by closed-circuit television.

\section{Ex Opera et Industria}

THE presidential address to the Institution of Mechanical Engineers at their meeting on October 27, 1965, was given by $\mathrm{H}$. N. G. Allen, deputy chairman and joint managing director, W. H. Allen, Sons and Co., Ltd., Bedford, and was entitled Ex Opera et Industria, a tribute to the Allen family motto, signifying (with implied overtones) 'by service freely given and by diligent application'. This tribute, which constituted the first part of the address, was an appreciation of the life-work of two eminent engineers, the late W. H. Allen, who took over a small jobbing company, Newberry and Co., Cardiff, in 1865 , thus founding the firm of W. H. Allen, and his eldest son, the late Sir Richard Allen. This first part is essentially historical, covering the years 1865-1955; but it sets the stage for what was, perhaps, the more important motive of this discourse, the second part, which considers "Unity of Purpose: Reflections and Queries". It is argued that in a rapidly changing world it may be questioned whether everyone concerned really understands what is meant by engineering, both in its own right and also as one vital organ of the complex living system which makes up a balanced industrial enterprise, and what kinds of engineer and engineering will be required in the future in industry. The answer to these and other pertinent questions raised by the president would appear to lie with the initiative for engineering co-ordination being within the province of the Council of Engineering Institutions, recently granted its Royal Charter. $\mathrm{Mr}$. Allen's plea is for pooling of ideas to get these actions moving. Reappraisal of the term 'engineering' in depth, breadth and context is required, and implicit in this is the conception, creation or utilization of an engineering product. Next, investigation of the different kinds of engineering required and of the relationship of engineers and engineering technicians is needed along with re-examination of educational and training requirements; finally, to present a unified front to schools on the meaning of engineering, career patterns available, and to consider educational and training programmes to this end. "If Science is knowledge and Engineering is applied knowledge, surely Wisdom is knowing how and when to apply that knowledge." The title of this address is one which Mr. Allen thinks might well be adopted by all engineers. His remarks must have given his audience much to think about and will doubtless lead to healthy repercussions throughout the professions and industry. The address is in the course of publication by the Institution of Mechanical Engineers.

\section{Scientific Research in Schools}

The Report to Council, 1965, of the Scientific Research in Schools Committee of the Royal Society has recently been published (Pp. 18. London: The Royal Society, 1965). The scheme, under which a committee of the Royal Society gives assistance to teachers of science to carry out research, has been in existence for 8 years. One hundred and seventeen teachers are now working under it, each being advised by a designated expert, and their investigations extend into ten major branches of science. Over the past year, $£ 5,472$ was expended in giving financial assistance to teachers, the strain on the Royal Society's own resources being in part relieved through contributions from eleven companies and the United Kingdom Atomic Energy Authority. In the opinion of the Royal Society, there is scope for further extension of the scheme, which is looked on favourably by head teachers and deserves to be more widely known.

\section{South Australian Museum}

The Records of the South Australian Museum includes an obituary and bibliography of the late Dr. H. M. Hale, director of the Museum from 1931 until 1960 (15, No. 1; 1965). Other articles include a revision of the Australian and New Guinea Drymini, Aboriginal rock poundings on Gallery Hill, North-western Australia, and new species of Holachila from Victoria and southern New South Wales. It is interesting to note that the rock poundings are the result of battering the surface of the rock with a rounded stone until the dark-coloured patina is destroyed, leaving a white mark as the shape of the design. The Records maintains its high standards of scholarship, illustrations and general format.

\section{Auckland Institute and Museum}

The Records of the Auckland Institute and Museum (6, No. 2, October 15,1965$)$ is, as usual, well illustrated and includes three papers by Mr. W. F. Ponder on the family Eatoniellidae, a revision of a recent species previously known as Notosetia Iredale and the recent and fossil species of Estea Iredale, respectively, all from Now Zealand. The final paper, by A. W. B. Powell, deals with molluscan systematics. 